\title{
Comparative population genetics of the invasive mosquito Aedes albopictus and the native mosquito Aedes flavopictus in the Korean peninsula
}

\author{
Jiyeong Shin ${ }^{1}$ and Jongwoo Jung ${ }^{1,2^{*}}$ (I)
}

\begin{abstract}
Background: Aedes mosquitoes are important invasive species contributing to the spread of chikungunya, dengue fever, yellow fever, zika virus, and other dangerous vector-borne diseases. Aedes albopictus is native to southeast Asia, with rapid expansion due to human activity, showing a wide distribution in the Korean peninsula. Aedes flavopictus is considered to be native to East Asia, with a broad distribution in the region, including the Korean peninsula. A better understanding of the genetic diversity of these species is critical for establishing strategies for disease prevention and vector control.
\end{abstract}

Methods: We obtained DNA from 148 specimens of Ae. albopictus and 166 specimens of Ae. flavopictus in Korea, and amplified two mitochondrial genes (COI and ND5) to compare the genetic diversity and structure of the two species.

Results: We obtained a 658-bp sequence of $\mathrm{CO}$ and a 423 -bp sequence of ND5 from both mosquito species. We found low diversity and a nonsignificant population genetic structure in Ae. albopictus, and high diversity and a nonsignificant structure in Ae. flavopictus for these two mitochondrial genes. Aedes albopictus had fewer haplotypes with respect to the number of individuals, and a slight mismatch distribution was confirmed. By contrast, Ae. flavopictus had a large number of haplotypes compared with the number of individuals, and a large unimodal-type mismatch distribution was confirmed. Although the genetic structure of both species was nonsignificant, Ae. flavopictus exhibited higher genetic diversity than Ae. albopictus.

Conclusions: Aedes albopictus appears to be an introduced species, whereas Ae. flavopictus is endemic to the Korean peninsula, and the difference in genetic diversity between the two species is related to their adaptability and introduction history. Further studies on the genetic structure and diversity of these mosquitos will provide useful data for vector control.

Keywords: Aedes albopictus, Aedes flavopictus, Population structure, Genetic diversity

*Correspondence: jongwoo@ewha.ac.kr

${ }^{1}$ The Division of EcoCreative, Ewha Womans University, Seoul 03760, South Korea

Full list of author information is available at the end of the article

\section{Background}

Arthropod-borne viruses are transmitted by blood-sucking insects to animals and humans. Most of them are transmitted by mosquitoes $[1,2]$. There are 43 genera and 3583 species of mosquitoes in the world; however, species belonging to the genera Aedes, Anopheles, and Culex are the main vectors of mosquito-borne diseases [3, 4]. In original author(s) and the source, provide a link to the Creative Commons licence, and indicate if changes were made. The images or other third party material in this article are included in the article's Creative Commons licence, unless indicated otherwise in a credit line to the material. If material is not included in the article's Creative Commons licence and your intended use is not permitted by statutory regulation or exceeds the permitted use, you will need to obtain permission directly from the copyright holder. To view a copy of this licence, visit http://creativecommons.org/licenses/by/4.0/. The Creative Commons Public Domain Dedication waiver (http://creativeco mmons.org/publicdomain/zero/1.0/) applies to the data made available in this article, unless otherwise stated in a credit line to the data. 
particular, mosquitoes belonging to the genus Aedes are the main vectors for spreading fatal diseases such as chikungunya, dengue fever, yellow fever, and Zika virus, that often occur in Asian countries [5-7]. As mosquito-borne diseases may grow in the future due to fast globalization and climate change, information on genetic studies effective in vector monitoring is needed to prevent infectious diseases [2, 8].

Mitochondrial genes are widely used in research on molecular evolution and population genetics of vector insects. Because they have a relatively high mutation rate and high levels of polymorphism and divergence due to their inherent sensitivity, they are highly useful as molecular markers [9-12]. Many vector studies have investigated where the population was introduced using mitochondrial genes $[13,14]$. In particular, there have been many studies using COI and ND5 as markers, for example, to determine whether a species has been introduced or to determine the genetic diversity of a population $[15,16]$. Population structure and genetic diversity between populations can affect vector capacity [17]. An understanding of these factors is necessary for vector control [18].

Aedes albopictus, originally from Southeast Asia, has recently spread throughout all parts of the world except Antarctica, and is considered one of the most dangerous alien species [19-21]. The first record of Ae. albopictus in South Korea was in 1940, and its distribution has recently expanded throughout the Korean peninsula [22, 23]. Together with Aedes aegypti, substantial research attention has been paid to Ae. albopictus as major players in the transmission of vector-borne diseases [24-26]. The main reason for the global spread is that larvae are introduced through used tires, bamboo, etc., due to human activities [27, 28]. Additionally, the range of habitats they can live in has widened as a result of the temperature rise due to global warming [29, 30]. Eggs of Ae. albopictus have been shown to tolerate cold weather, and have the potential to expand its distribution in colder regions [31, 32].

Aedes flavopictus is known to be native to East Asia, and is divided into three subspecies depending on the region. The subspecies are morphologically and genetically distinct [33, 34]: Ae. flavopictus, Ae. flavopictus downsi, and Ae. flavopictus miyarai. Among the three, Ae. flavopictus is distributed in the Korean Peninsula, and records show that they have existed here for a long time, but there have been few molecular studies on this species, so the extent of its genetic diversity is not fully known [33, 35, 36]. Aedes flavopictus eggs have been found to survive in colder environments than Ae. albopictus eggs [37], and the distribution of eggs has expanded from East Asia to European countries in recent times
[38-40]. According to the results of continuous monitoring on the Korean Peninsula, the frequency of appearance of Ae. flavopictus is not high [23, 41-43]. Aedes flavopictus is not known to act as a vector like Ae. albopictus and other Aedes species, but it has previously been shown that it may propagate dengue fever [33, 44, 45].

Since the two species are distributed over a wide area in Korea and Japan and share a common habitat [34, 46, 47], research on their overlapping distribution is gradually increasing. Furthermore, there is a possibility of interspecific crossing [48-50]. Not only do the distributions overlap, but the two morphologies are also similar $[34,40,51]$, and Japanese studies have shown that the two are phylogenetically close to each other [52, 53]. As Ae. albopictus and Ae. flavopictus are closely related species and have similar ecological roles and habitats, they can be compared to each other.

The Korean Peninsula has various climates and geographical environments, and the diversity of arthropods that transmit arthropod-borne viruses is also high [54, 55]. There are 11 genera and 56 species of mosquitoes in Korea, including 19 species in the genus Aedes. The presence of Ae. albopictus and Ae. flavopictus was recorded in Korea in the past $[22,35,56,57]$. Since malaria and Japanese encephalitis occur frequently in Korea, studies have only focused on the vectors of these conditions, and the genus Aedes has not been thoroughly investigated [58-60]. There are cases in which foreign mosquitoes have become indigenous, thereby bringing infections from abroad. Additionally, Korea has steadily imported patients, so it is not possible to say that it is a clean country for viruses mediated by Aedes; therefore, a preemptive control strategy needs to be established [61, 62].

This study compares the genetic diversity and genetic structure of two species of Aedes mosquitoes living in Korea using two mitochondrial genes, with the aim of monitoring mosquito populations. With this work, we intend to create genetic data that infer the genetic state of vectors, to establish a vector control strategy.

\section{Methods}

\section{Sampling and DNA extraction}

A total of 314 individual mosquitos were sampled in Korea between 2017 and 2020, including 148 individuals of Ae. albopictus from 19 locations and 166 individuals of Ae. flavopictus from 14 locations (Fig. 1). All specimens were sampled from the forests, parks and rural areas (Additional file 1: Figures S1-S3). Adult mosquitoes were collected using nets and BG-Sentinel traps (Biogents AG, Germany). All mosquitoes were identified according to the Korean mosquito taxonomic keys $[22,57]$. These two species differ in the patch at the root of the front wing. Specimens were individually preserved in tubes filled 


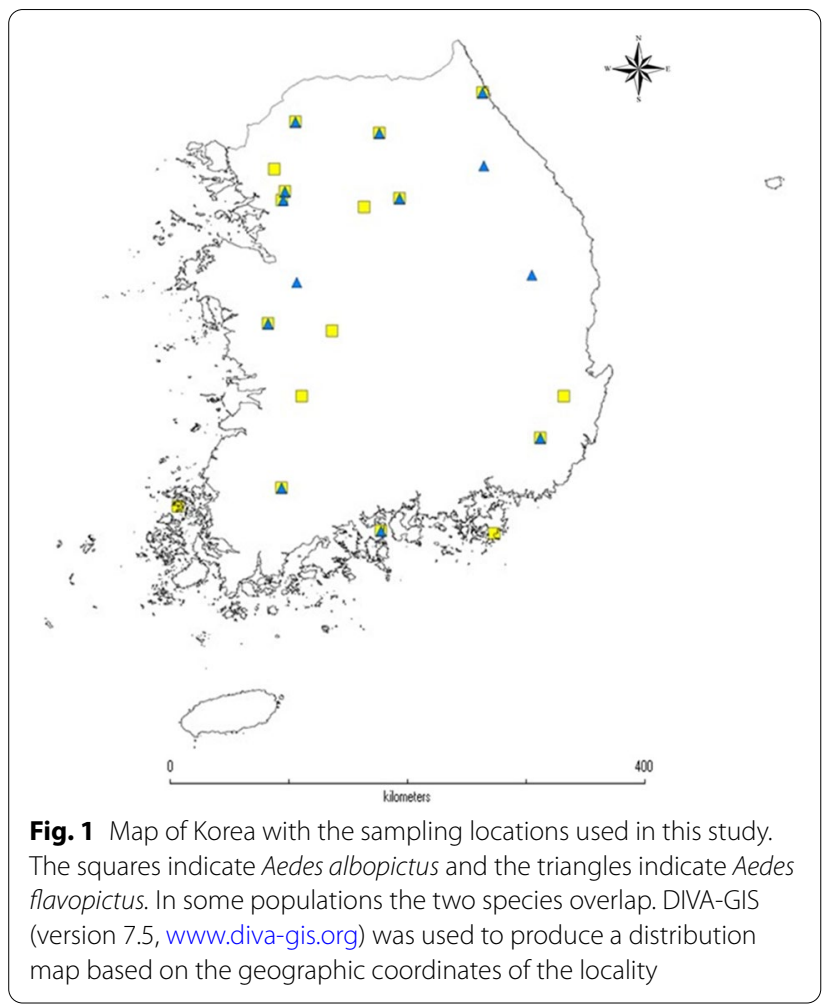

with $80 \%$ ethanol and stored at $4{ }^{\circ} \mathrm{C}$ until DNA extraction. DNA was extracted from one to three legs of each sample using the DNeasy Blood \& Tissue Kit (Qiagen, Valencia, CA, USA).

\section{Polymerase chain reaction (PCR) and sequencing}

Two regions of mitochondrial genes (COI and ND5) were amplified by PCR using the following primer pairs: albCOIF (5'-TTTCAACAAATCATAAAGATATTGG-3') and albCOIR (5'-TAA ACTTCTGGATGACCAAAA AATCA-3') for COI [63], and ND5_6500F (5'-TCCTTA GAATAAAATCCCGC-3') and ND5_7398R (5'-GTT TCTGCTTTAGTTCATTCTTC-3') for ND5 [64]. For COI, PCR amplifications were performed in a $25 \mu \mathrm{l}$ reaction volume containing $0.5 \mu \mathrm{l}$ of isolated DNA, $2.5 \mu \mathrm{l}$ of $10 \times$ Taq buffer, $2.0 \mu \mathrm{l}$ of $\mathrm{MgCl}_{2}(25 \mathrm{mM}), 0.7 \mu \mathrm{l}$ of dNTP solution (2.5 mM each), $0.5 \mu \mathrm{l}$ of each primer, and $0.3 \mu \mathrm{l}$ of Taq DNA polymerase (Takara Bio Inc., Kusatsu, Shiga, Japan). The PCR cycling conditions were as follows: an initial denaturation step at $95{ }^{\circ} \mathrm{C}$ for $5 \mathrm{~min}$; followed by 35 cycles of denaturation at $95{ }^{\circ} \mathrm{C}$ for $30 \mathrm{~s}$, annealing at $45{ }^{\circ} \mathrm{C}$ for $30 \mathrm{~s}$, and elongation at $72{ }^{\circ} \mathrm{C}$ for $45 \mathrm{~s}$; with a final extension at $72{ }^{\circ} \mathrm{C}$ for $7 \mathrm{~min}$. For ND5, the PCR mixture was the same as that used for COI. The amplification conditions were as follows: initial denaturation at $98^{\circ} \mathrm{C}$ for $5 \mathrm{~min}$; followed by 10 cycles at $95^{\circ} \mathrm{C}$ for $1 \mathrm{~min}$, $45{ }^{\circ} \mathrm{C}$ for $1 \mathrm{~min}$, and $72{ }^{\circ} \mathrm{C}$ for $1 \mathrm{~min} 30 \mathrm{~s} ; 30$ cycles at $95^{\circ} \mathrm{C}$ for $1 \mathrm{~min}, 46{ }^{\circ} \mathrm{C}$ for $1 \mathrm{~min}$, and $72{ }^{\circ} \mathrm{C}$ for $1 \mathrm{~min} 30 \mathrm{~s}$; and a final extension at $72{ }^{\circ} \mathrm{C}$ for $3 \mathrm{~min}$. PCR products were separated by $2 \%$ agarose gel electrophoresis (SigmaAldrich, Germany) and sequenced by Cosmo Genetech (Seoul, Korea) using the ABI 3730xl DNA Analyzer (Applied Biosystems, Foster City, CA, USA).

\section{Data analyses}

The sequences of the two mitochondrial genes were aligned using the ClustalW plugin on Geneious Prime 2020.1.2 (https://www.geneious.com) and prepared as concatenated sequences. DnaSP 6.12 .03 [65] was used for the genetic diversity analysis of mitochondrial DNA, in which the number of haplotypes $(H)$, number of segregating sites $(S)$, haplotype diversity $(\mathrm{Hd})$, nucleotide diversity $(\pi)$, and average number of nucleotide differences $(k)$ were examined.

Pairwise $F_{\mathrm{ST}}$ values were estimated using Arlequin 3.5 software [66] to investigate genetic differentiation among the populations. Principal coordinate analysis (PCoA) was performed with GenAlEx version 6.51b2 [67] based on pairwise $F_{\mathrm{ST}}$ values.

Analyses of molecular variance (AMOVA) were performed using Arlequin 3.5 [66] with the locus-by-locus option and using 1000 permutations to determine the population structure. Specimens were grouped according to regional groups in South Korea: Group 1 comprised specimens from Gyeonggi-do, Group 2, Gangwon-do; Group 3, Chungcheong-do; Group 4, Gyeongsang-do, and Group 5, Jeolla-do.

To better understand the genealogical relationships, the haplotypes were constructed using the TCS method as implemented in PopART 1.7 [68].

To investigate the demographic history of populations, deviations from selective neutrality were tested by Tajima's $D$ [69] and Fu's $F_{\mathrm{S}}$ [70] metrics using Arlequin 3.5 [66]. To confirm whether a population had undergone sudden expansion, a mismatch distribution was determined using DnaSP 6.12.03 [65].

\section{Results}

Mitochondrial gene sequence analysis resulted in a $\mathrm{CO} 1$ sequence of $658 \mathrm{bp}$ and an ND5 sequence of $423 \mathrm{bp}$ in the 19 populations (148 individuals) of Ae. albopictus, and sequences of the same length were obtained for the 14 populations (166 individuals) of Ae. flavopictus (Additional file 2: Table S1). The average winter temperature and average precipitation during the sampling year were obtained based on data from the Korea Meteorological Agency (https://data.kma.go.kr/cmmn/main.do). In the two mitochondrial DNA concatenated sequences, there were 25 haplotypes in Ae. albopictus and 107 haplotypes in Ae. flavopictus. 
The genetic diversity analysis revealed a relatively low number of haplotypes in Ae. albopictus compared to the total number of individuals, with relatively low haplotype diversity (0.396) and nucleotide diversity (0.00075) in the entire population. The highest haplotype diversity was found for the 2018 Anyang and Gyeongju populations, and the lowest values were 0 for six populations. The 2018 Anyang and Gyeongju populations also exhibited the highest nucleotide diversity. Ae. flavopictus showed a relatively high number of haplotypes compared to the total number of individuals, and high levels of haplotype diversity (0.990) and nucleotide diversity (0.00894) were found in the entire population. Analysis of the two species revealed that Ae. flavopictus exhibited higher levels in various genetic diversity indices (Table 1 ).

Aedes albopictus showed nonsignificant pairwise $F_{\mathrm{ST}}$ values overall, but the Geoje population showed a high level of significance in structure compared to the other populations. By contrast, Ae. flavopictus showed low overall $F_{\mathrm{ST}}$ values, among which those of the Yeosu and Yeoncheon populations were significant (Fig. 2; Additional file 3: Tables S2, S3). In both species, there were no significant pairwise $F_{\mathrm{ST}}$ values among domestic populations except for a few populations.

AMOVA showed low genetic variance among both species, but high variance within populations. In particular,

Table 1 Sampling locations, summary of molecular diversity for each species of this study

\begin{tabular}{|c|c|c|c|c|c|c|c|c|c|}
\hline Species & Population & Sample size & $H$ & $S$ & k & $\mathrm{Hd}$ & $\pi$ & Tajima's D & Fu's $F_{S}$ \\
\hline \multirow[t]{19}{*}{ Aedes albopictus } & 2017_Wonju & 18 & 5 & 4 & 0.725 & 0.549 & 0.00067 & -1.12822 & -2.0958 \\
\hline & 2020_Wonju & 18 & 2 & 3 & 0.333 & 0.111 & 0.00031 & -1.71304 & 0.65061 \\
\hline & Yeoncheon & 5 & 1 & 0 & 0 & 0 & 0 & 0 & 0 \\
\hline & Yangsan & 12 & 6 & 4 & 1.152 & 0.758 & 0.00107 & -0.45947 & -2.89747 \\
\hline & 2020_Anyang & 4 & 2 & 1 & 0.500 & 0.500 & 0.00046 & -0.61237 & 0.17185 \\
\hline & 2018_Anyang & 4 & 4 & 6 & 3.167 & 1.000 & 0.00293 & -0.31446 & -1.15708 \\
\hline & Chuncheon & 7 & 1 & 0 & 0 & 0 & 0 & 0 & 0 \\
\hline & Cheongyang & 2 & 1 & 0 & 0 & 0 & 0 & 0 & 0 \\
\hline & Daejeon & 8 & 1 & 0 & 0 & 0 & 0 & 0 & 0 \\
\hline & Gwacheon & 7 & 3 & 2 & 0.571 & 0.524 & 0.00053 & -1.23716 & -0.9218 \\
\hline & Geoje & 5 & 2 & 1 & 0.600 & 0.600 & 0.00056 & 1.22474 & 0.62615 \\
\hline & Gwangju & 2 & 1 & 0 & 0 & 0 & 0 & 0 & 0 \\
\hline & Gyeongju & 2 & 2 & 3 & 3.000 & 1.000 & 0.00278 & 0 & 1.09861 \\
\hline & Jeung-do & 5 & 3 & 2 & 1.000 & 0.800 & 0.00093 & 0.24314 & -0.47542 \\
\hline & Jeonju & 28 & 3 & 2 & 0.143 & 0.140 & 0.00013 & -1.5106 & -2.26798 \\
\hline & Sokcho & 13 & 3 & 2 & 0.308 & 0.295 & 0.00028 & -1.46801 & -1.40150 \\
\hline & Seoul & 3 & 2 & 1 & 0.667 & 0.667 & 0.00062 & 0 & 0.20067 \\
\hline & Yeoju & 3 & 1 & 0 & 0 & 0 & 0 & 0 & 0 \\
\hline & Yeosu & 2 & 1 & 0 & 0 & 0 & 0 & 0 & 0 \\
\hline \multirow[t]{14}{*}{ Aedes flavopictus } & 2017_Wonju & 6 & 6 & 19 & 8.667 & 1 & 0.00802 & 0.25884 & -1.18145 \\
\hline & 2017_Uiwang & 21 & 16 & 50 & 15.281 & 0.971 & 0.01414 & 0.39649 & -1.61069 \\
\hline & 2020_Uiwang & 10 & 9 & 29 & 9.089 & 0.978 & 0.00841 & -0.54358 & -1.86104 \\
\hline & Yeoncheon & 2 & 2 & 1 & 1.000 & 1 & 0.00093 & 0 & 0 \\
\hline & Yangsan & 17 & 14 & 26 & 6.75 & 0.971 & 0.00624 & -0.49372 & -5.0955 \\
\hline & Asan & 22 & 15 & 49 & 9.779 & 0.939 & 0.00905 & -1.07423 & -2.0798 \\
\hline & Bonghwa & 18 & 16 & 25 & 5.693 & 0.987 & 0.00527 & -0.86027 & -9.17073 \\
\hline & Chuncheon & 2 & 2 & 9 & 9 & 1 & 0.00833 & 0 & 2.19722 \\
\hline & Cheongyang & 9 & 8 & 15 & 4.944 & 0.972 & 0.00457 & -0.50238 & -2.75282 \\
\hline & Gwacheon & 10 & 9 & 26 & 10.133 & 0.978 & 0.00937 & 0.48927 & -1.59674 \\
\hline & Gwangju & 17 & 8 & 33 & 7.721 & 0.816 & 0.00714 & -0.85617 & 1.62731 \\
\hline & Pyeongchang & 9 & 7 & 27 & 8.861 & 0.917 & 0.00820 & -0.53942 & 0.02987 \\
\hline & Sokcho & 6 & 5 & 14 & 5.333 & 0.933 & 0.00493 & -0.79924 & -0.2382 \\
\hline & Yeosu & 17 & 6 & 20 & 5.412 & 0.691 & 0.00501 & -0.33724 & 2.44814 \\
\hline
\end{tabular}


a

Principal Coordinate (PCoA)

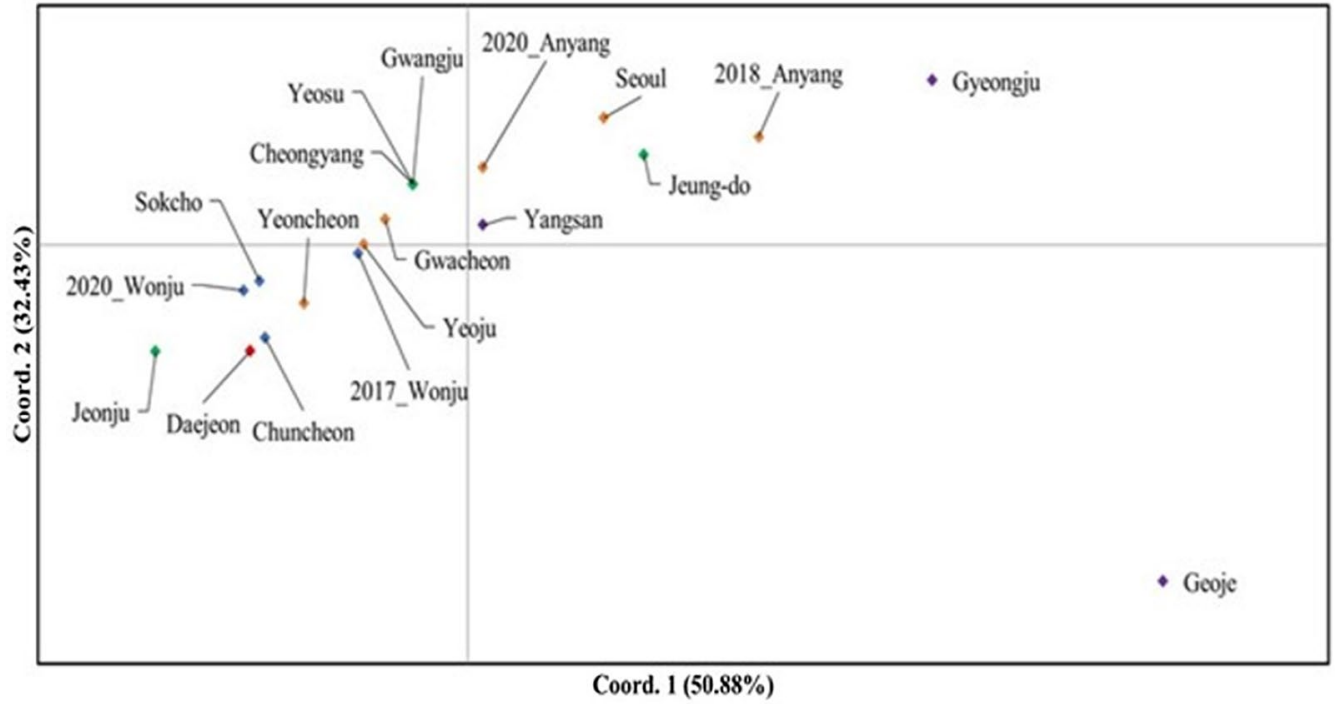

b Principal Coordinate (PCoA)

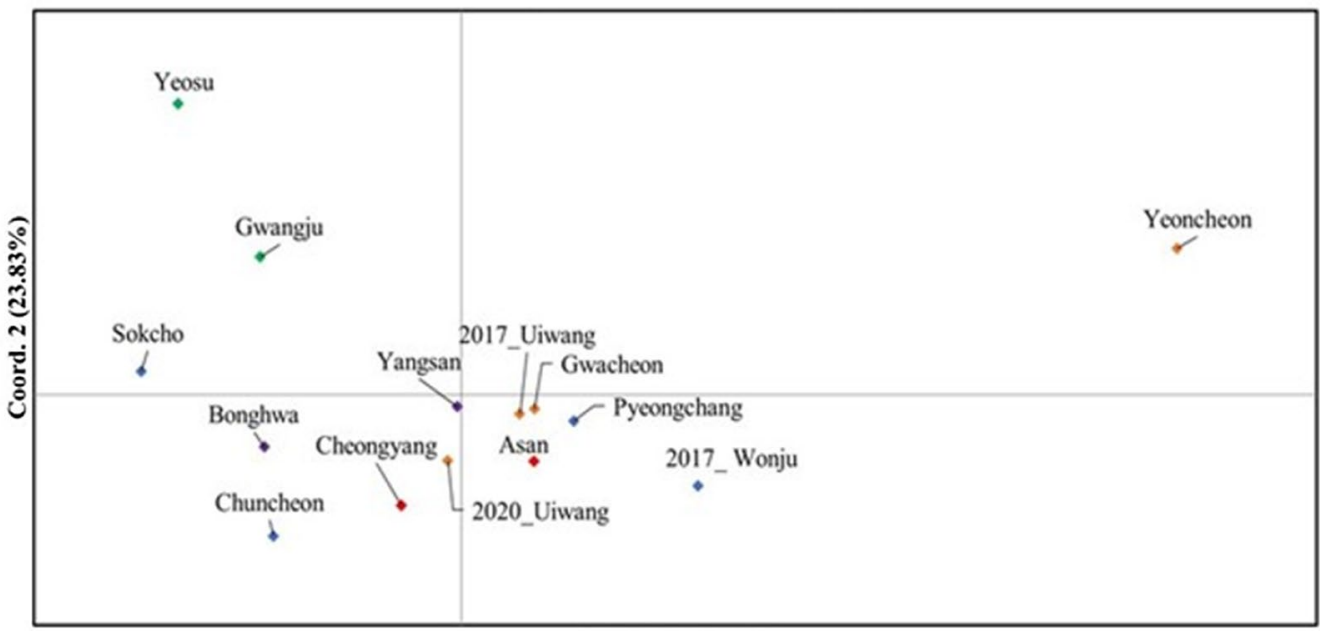

Coord. $1(34.72 \%)$

Fig. 2 Principal coordinate analysis (PCOA) plot of pairwise population $F_{S T}$ values for the locations sampled in Korea in this study. a Aedes albopictus; b Aedes flavopictus

Ae. flavopictus showed higher variance than Ae. albopictus, indicating that it can form a genetic structure within populations (Table 2).

In the haplotype network, Ae. albopictus showed a simple star-like form, in which several haplotypes diverged from one of the largest haplotypes, and hap_1 had the highest frequency of $78 \%$ in all populations. Private haplotypes, most of which were singleton haplotypes, accounted for $22 \%$. Aedes flavopictus exhibited a complex haplotype network, which was found to have a higher haplotype frequency compared to the total number of individuals. Most of the network was composed of singleton haplotypes. When comparing the two species, Ae. flavopictus had more haplotypes than Ae. albopictus and showed a complex haplotype network (Fig. 3).

With respect to demographic history, Ae. albopictus showed negative but low values for Tajima's $D(-0.36713)$ and Fu's $F_{S}(-0.44574)$ in the whole population. Negative values of Tajima's $D(-0.34726)$ and Fu's $F_{S}(-1.37746)$ were also found for the entire population of Ae. flavopictus. In both species, Ae. flavopictus showed negative Fu's $F_{S}$ values. For the mismatch distribution, the result of $A e$. 
Table 2 Analysis of molecular variance (AMOVA) of this study

\begin{tabular}{llrr}
\hline Species & Source of variation & Degrees of freedom & $\begin{array}{c}\text { Percentage of } \\
\text { variation (\%) }\end{array}$ \\
\hline Aedes albopictus & Among groups & 4 & -5.6 \\
& Among populations within groups & 14 & 46.4 \\
& Within populations & 129 & 59.2 \\
Aedes flavopictus & Among groups & 4 & 4.0 \\
& Among populations within groups & 9 & 9.6 \\
& Within populations & 152 & 86.3 \\
\hline
\end{tabular}

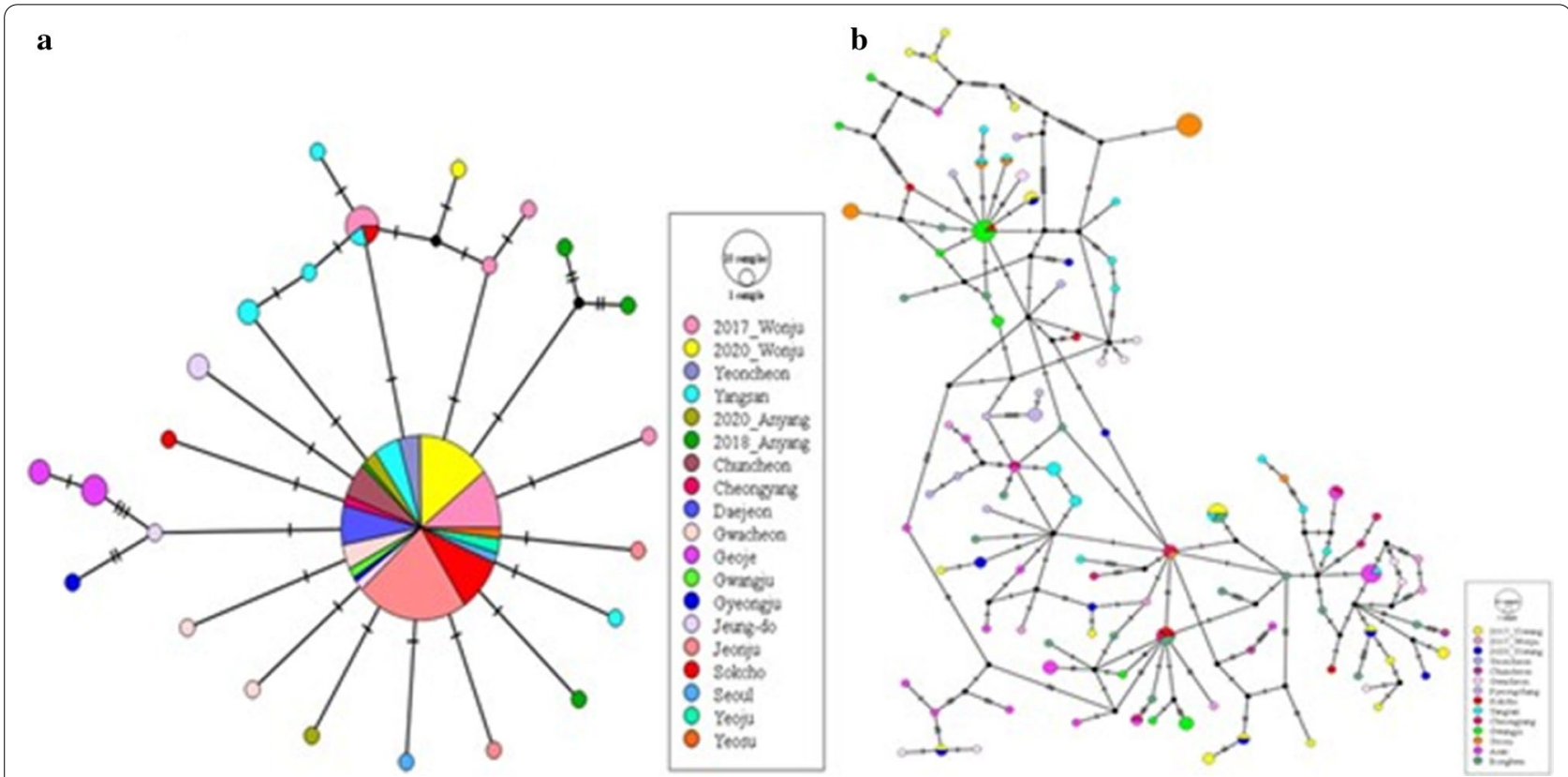

Fig. 3 TCS networks constructed with PopART for haplotypes. a Aedes albopictus; b Aedes flavopictus. Circle sizes reflect haplotype abundance and percentage of color in the circles shows the haplotype frequency

albopictus was nonsignificant, whereas Ae. flavopictus showed a large unimodal shape, indicating the possibility of sudden expansion of the population (Fig. 4).

\section{Discussion}

Based on the above results, two conclusions can be drawn. Higher genetic diversity was observed in Ae. flavopictus than in Ae. albopictus, and the two species of mosquitoes generally showed low levels of genetic structure except for some populations.

There are two hypotheses addressing the overall low diversity of Ae. albopictus in Korea. The first concerns the spread of Wolbachia to the mitochondria: in many arthropods, selective sweeps arising from widespread Wolbachia infections often lead to low diversity, therefore posing a high possibility of unreliable results [71]. Previous studies have shown that intracellular Wolbachia was detected in 17 populations in Korea, and these groups are known to have low mitochondrial diversity [72, 73]. However, there is no clear evidence of Wolbachia in many samples, and further analysis of the nuclear genes, as well as the mitochondrial genes, will be needed to reveal the impact of Wolbachia on genetic diversity in the population [72, 74]. The second hypothesis is that the introduced Ae. albopictus may have been affected by Korea's harsh winter climate, which is different from that of the country of origin. Ae. albopictus is considered to be an invasive species that has recently spread abroad from its origin in Southeast Asia [19, 20]. These mosquitos have adapted to the environment of each country since their introduction, but previous studies have shown that they also have low diversity in the countries from which they were introduced $[13,15]$. The environment in Southeast Asia, the native habitat of Ae. albopictus, is hot and humid, facilitating the spread of Ae. albopictus [75]. However, winters are quite severe in Korea, with 

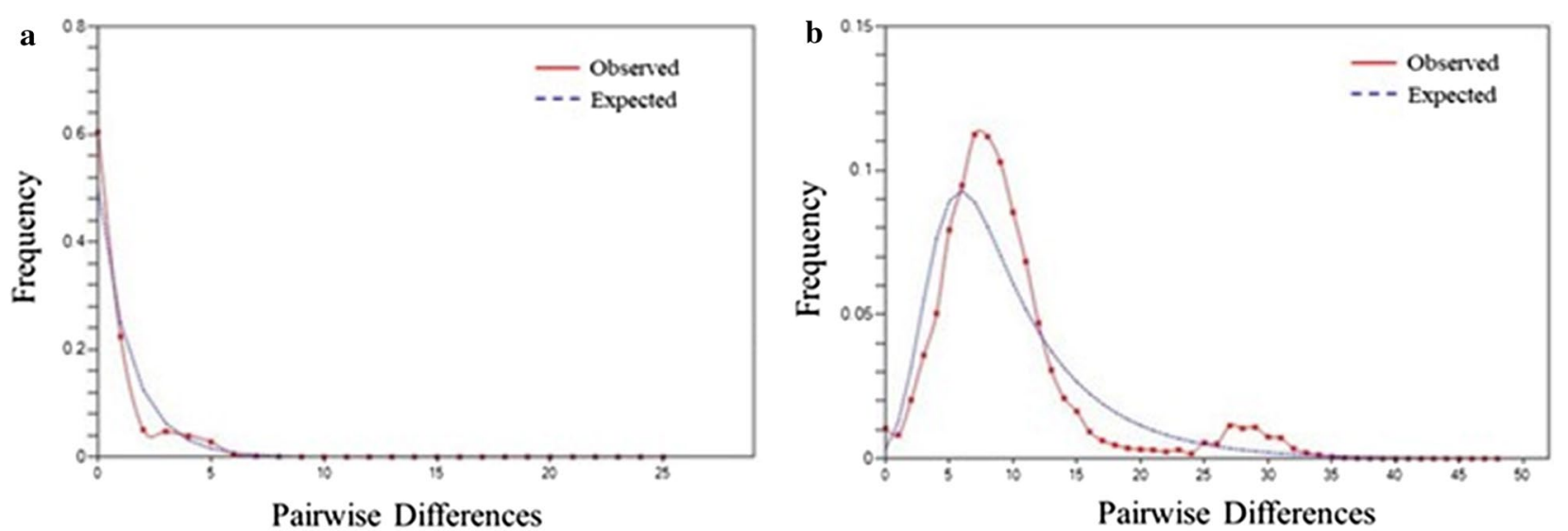

Fig. 4 Mismatch distribution of two species populations in Korea. a Aedes albopictus; b Aedes flavopictus

cold, dry weather. The average temperature is less than $10{ }^{\circ} \mathrm{C}$. This environment could lead to a decrease in the population size of this mosquito, resulting in decreased genetic diversity $[60,76]$. In the domestic populations, the Geoje population is different from other populations. This is believed to arise from genetic differences due to the physical distance between mosquitoes introduced by human activities. The distance traveled by mosquitoes in the natural environment is, however, only a few kilometers [77], and there are study results showing that the populations have been genetically structured in heterogeneous habitats due to their limited dispersive abilities [78].

Korean Ae. flavopictus have high genetic diversity and a complex haplotype network. There are two hypotheses regarding their high diversity. The first is based on the fact that Ae. flavopictus is endemic to East Asia. Studies on mosquitoes of the genus Aedes show that genetic diversity in the original population is much higher, which supports the contention that the original population of Ae. flavopictus is Korean $[79,80]$. The second hypothesis considers the adaptation to cold climates as an endemic species: Ae. flavopictus is an Asian species that does not exist in tropical regions, and lives in subtropical areas throughout the cool-temperate region [53]. This mosquito species has recently been found in the Netherlands, a more northerly region, and is considered highly likely to spread due to its ability to cope with environmental changes [39, 40]. Aedes flavopictus has excellent environmental adaptability, and its eggs can survive in cold and dry conditions for long periods [35, 81]. Studies have also shown that it is genetically close to Aedes galloisi, a northern mosquito species in the same genus [52].

Differences in diversity between Ae. albopictus and Ae. flavopictus can be explained in several ways. A small mismatch in distribution and a single haplotype shared by various populations indicate that the patterns observed in Ae. albopictus may have been affected by a decrease in effective population size, human introduction, and natural environmental changes [13, 15, 82, 83]. Environmental and biological barriers, and factors such as human activity, climate change, migration, and genetic flow can affect the genetic diversity and structure of species [84]. Aedes flavopictus, an endemic species, shows high genetic diversity, a large unimodal mismatch distribution, and a complex haplotype network. However, the unimodal form of its mismatch distribution indicates that the Ae. flavopictus population may have recently experienced a large population expansion. This successful distribution and increasing population of the endemic Ae. flavopictus may have been affected by human demographics [25]; further, the complex form of the haplotype network indicates a high mutation rate, which can increase the rate of resistance development in insects [85, 86]. The difference in genetic diversity between these two mosquito species living in Korea may also arise from the differences in effective population size due to their ability to adapt to the cold as well as their status as an endemic or introduced species. Although the distribution of these two species overlaps, Ae. albopictus can survive for up to $24 \mathrm{~h}$ at $-10{ }^{\circ} \mathrm{C}$ in the form of diapause eggs [87], and the eggs of Ae. flavopictus can survive for a longer period $[35,37,53]$. The decreased survival rate of eggs can affect the effective population size, as fewer adults develop [88, 89]. This difference in cold adaptation and consequent effects on the size of the effective population can lead to differences in genetic diversity [60, 90,91]. Monitoring of vectors in Korea has shown that the frequency of Ae. flavopictus appearance was not high, but the reason for the large potential population size in this study lies in the difference between the location and the collection method [23, 41-43]. Thus, continuous monitoring is needed 
because this species is highly likely to affect humans, as it has a large population size and considerable potential as a vector.

The differences in the genetic diversity of Ae. albopictus and Ae. flavopictus populations revealed in this study suggest that the continuous monitoring of these species with multiple possibilities as vectors is essential. To understand the genetic diversity of Aedes mosquito species in Korea, sampling in more diverse regions and the use of different genetic markers will be conducted in further studies.

\section{Conclusions}

This is the first paper comparing genetic diversity and the genetic structure of two Aedes mosquito species inhabiting Korea. The results showed that Ae. albopictus, which is considered to be an introduced species, has lower genetic diversity than Ae. flavopictus, the endemic species. The low diversity of Ae. albopictus suggests that these mosquitos were introduced by humans, but did not fully adapt to the environment of the Korean Peninsula. The high diversity of Ae. flavopictus could be due to its greater adaptability to the environment of the Korean Peninsula as an endemic species, but may also be influenced by an increase in population and resistance to pesticides. However, in light of the rising temperatures caused by climate change, the domestic inflow of patients, and the population density, the Korean Peninsula will continue to face the threat of mosquito-borne diseases. Studies of the genetic status of potential vector species will provide useful data for inferring effective population sizes and monitoring and managing mosquito populations.

\section{Abbreviations}

COI: Cytochrome c oxidase subunit l; ND5: NADH dehydrogenase subunit 5.

\section{Supplementary Information}

The online version contains supplementary material available at https://doi. org/10.1186/s13071-021-04873-5.

Additional file 1: Figure S1. Representative picture of a forest area surveyed in this study in Korea. Figure S2. Representative picture of a rural area surveyed in this study in Korea. Figure S3. Representative picture of a park surveyed in this study in Korea.

Additional file 2: Table S1. Details of the mosquito populations used in this study, with GenBank accession numbers for $\mathrm{CO} 1$ and ND5 gene sequences.

Additional file 3: Table S2. Pairwise $F_{\text {ST }}$ values obtained using two mitochondrial DNA concatenated sequences from Aedes albopictus. Table S3. Pairwise $F_{\text {ST }}$ values obtained using two mitochondrial DNA concatenated sequences from Aedes flavopictus.

Acknowledgements

The authors thank all the students who participated in this study.

\section{Authors' contributions}

JS performed practical work and JJ monitored the study. JS analyzed the data and drafted the manuscript with JJ. Both authors read and approved the final manuscript.

\section{Funding}

This work was supported by the National Research Foundation of Korea (NRF) grant funded by the Korea government (MSIT) (No. 2017R1D1 A2B04033088).

\section{Availability of data and materials}

Accession numbers for mitochondrial DNA sequences generated in this study are in Additional file 2: Table S1.

\section{Declarations}

Ethics approval and consent to participate

Not applicable.

\section{Consent for publication}

Not applicable.

\section{Competing interests}

The authors declare no competing interests.

\section{Author details}

${ }^{1}$ The Division of EcoCreative, Ewha Womans University, Seoul 03760, South Korea. ${ }^{2}$ Department of Science Education, Ewha Womans University, Seoul 03760, South Korea.

Received: 20 February 2021 Accepted: 7 July 2021

Published online: 27 July 2021

\section{References}

1. Gubler DJ. The global emergence/resurgence of arboviral diseases as public health problems. Arch Med Res. 2002;33(4):330-42.

2. Reiter P. Climate change and mosquito-borne disease. Environ Health Perspect. 2001;109(suppl 1):141-61.

3. Levin ML. Medical entomology for students. Emerg Infect Dis. 2014;20:1428.

4. Harbach RE. Mosquito taxonomic inventory. http://mosquito-taxonomicinventory.info/ (2013). Accessed 02 May 2021.

5. Weetman D, Kamgang B, Badolo A, Moyes CL, Shearer FM, Coulibaly M, et al. Aedes mosquitoes and Aedes-borne arboviruses in Africa: current and future threats. Int J Environ Res Public Health. 2018;15(2):220.

6. Boyer S, Marcombe S, Yean S, Fontenille D. High diversity of mosquito vectors in Cambodian primary schools and consequences for arbovirus transmission. PLoS ONE. 2020;15(6):e0233669.

7. Morens DM, Folkers GK, Fauci AS. The challenge of emerging and reemerging infectious diseases. Nature. 2004;430(6996):242-9.

8. Im JH, Kim T-S, Chung M-H, Baek JH, Kwon HY, Lee J-S. Current status and a perspective of mosquito-borne diseases in the Republic of Korea. Vector Borne Zoonotic Dis. 2021;21 (2):69-77.

9. Avise JC, Arnold J, Ball RM, Bermingham E, Lamb T, Neigel JE, et al. Intraspecific phylogeography: the mitochondrial DNA bridge between population genetics and systematics. Annu Rev Ecol Evol Syst. 1987;18(1):489-522.

10. Tang J, Pruess K, Cupp EW, Unnasch TR. Molecular phylogeny and typing of blackflies (Diptera: Simuliidae) that serve as vectors of human or bovine onchocerciasis. Med Vet Entomol. 1996;10(3):228-34.

11. Opiro R, Saarman NP, Echodu R, Opiyo EA, Dion K, Halyard A, et al. Genetic diversity and population structure of the tsetse fly Glossina fuscipes fuscipes (Diptera: Glossinidae) in Northern Uganda: implications for vector control. PLoS Negl Trop Dis. 2017;1 (4):e0005485.

12. Kang S, Jung J, Kim W. Population genetic structure of the malaria vector Anopheles sinensis (Diptera: Culicidae) sensu stricto and evidence for possible introgression in the Republic of Korea. J Med Entomol. 2015;52(6):1270-81. 
13. Kamgang B, Wilson-Bahun TA, Irving H, Kusimo MO, Lenga A, Wondji CS. Geographical distribution of Aedes aegypti and Aedes albopictus (Diptera: Culicidae) and genetic diversity of invading population of Ae. albopictus in the Republic of the Congo. Wellcome Open Res. 2018. https://doi.org/ 10.12688/wellcomeopenres.14659.3.

14. Salgueiro P, Serrano C, Gomes B, Alves J, Sousa CA, Abecasis A, et al. Phylogeography and invasion history of Aedes aegypti, the Dengue and Zika mosquito vector in Cape Verde islands (West Africa). Evol Appl. 2019;12(9):1797-811.

15. Žitko T, Kovačić A, Desdevises Y, Puizina J. Genetic variation in East-Adriatic populations of the Asian tiger mosquito, Aedes albopictus (Diptera: Culicidae), inferred from NADH5 and COI sequence variability. Eur J Entomol. 2011;108(4):501-8.

16. Kamgang B, Ngoagouni C, Manirakiza A, Nakouné E, Paupy C, Kazanji M. Temporal patterns of abundance of Aedes aegypti and Aedes albopictus (Diptera: Culicidae) and mitochondrial DNA analysis of Ae. albopictus in the Central African Republic. PLoS Negl Trop Dis. 2013;7(12):e2590.

17. Failloux A-B, Vazeille M, Rodhain F. Geographic genetic variation in populations of the dengue virus vector Aedes aegypti. J Mol Evol. 2002;55(6):653-63.

18. McCoy K. The population genetic structure of vectors and our understanding of disease epidemiology. Parasite. 2008;15(3):444-8.

19. Medlock JM, Hansford KM, Schaffner F, Versteirt V, Hendrickx G, Zeller $\mathrm{H}$, et al. A review of the invasive mosquitoes in Europe: ecology, public health risks, and control options. Vector Borne Zoonotic Dis. 2012;12(6):435-47.

20. van der Weijden W, Leewis R, Bol P. 100 of the world's worst invasive alien species. Biological globalisation. Utrecht: KNNV Publishing; 2007. p. 206-8.

21. Paupy C, Delatte H, Bagny L, Corbel V, Fontenille D. Aedes albopictus, an arbovirus vector: from the darkness to the light. Microbes Infect. 2009;11(14-15):1177-85.

22. Rhee $H$. Taxonomic review and revised keys of the Korean mosquitoes (Diptera: Culicidae). Entomol Res. 2003;33(1):39-52.

23. Yang S, Lee E, Lee W, Shin-Hyeong C. Geographical distribution of Aedes albopictus around urban areas in Korea. Public Health Wkly Rep. 2018;11(15):463-8.

24. Giatropoulos A, Papachristos DP, Koliopoulos G, Michaelakis A, Emmanouel N. Asymmetric mating interference between two related mosquito species: Aedes (Stegomyia) albopictus and Aedes (Stegomyia) cretinus. PLoS ONE. 2015;10(5):e0127762.

25. Naim DM, Kamal NZM, Mahboob S. Population structure and genetic diversity of Aedes aegypti and Aedes albopictus in Penang as revealed by mitochondrial DNA cytochrome oxidase I. Saudi J Bio Sci. 2020;27(3):953-67.

26. Mousson L, Dauga C, Garrigues T, Schaffner F, Vazeille M, Failloux A-B. Phylogeography of Aedes (Stegomyia) aegypti (L.) and Aedes (Stegomyia) albopictus (Skuse)(Diptera: Culicidae) based on mitochondrial DNA variations. Genet Res. 2005;86(1):1-11.

27. Knudsen A. Global distribution and continuing spread of Aedes albopictus. Parassitologia. 1995;37(2-3):91-7.

28. Demeulemeester J, Deblauwe I, De Witte JC, Jansen F, Hendy A, Madder M. First interception of Aedes (Stegomyia) albopictus in Lucky bamboo shipments in Belgium. Eur Mosq Control Assoc. 2014;32:14-6.

29. Rochlin I, Ninivaggi DV, Hutchinson ML, Farajollahi A. Climate change and range expansion of the Asian tiger mosquito (Aedes albopictus) in Northeastern USA: implications for public health practitioners. PLOS ONE. 2013;8(4):e60874

30. Fischer D, Thomas S, Neteler M, Tjaden N, Beierkuhnlein C. Climatic suitability of Aedes albopictus in Europe referring to climate change projections: comparison of mechanistic and correlative niche modelling approaches. Euro Surveill. 2014;19(6):20696.

31. Tippelt L, Werner D, Kampen H. Tolerance of three Aedes albopictus strains (Diptera: Culicidae) from different geographical origins towards winter temperatures under field conditions in northern Germany. PLOS ONE. 2019;14(7):e0219553.

32. Tippelt L, Werner D, Kampen H. Low temperature tolerance of three Aedes albopictus strains (Diptera: Culicidae) under constant and fluctuating temperature scenarios. Parasites Vectors. 2020;13(1):1-12.

33. Toma T, Miyagi I, Crabtree MB, Miller BR. Investigation of the Aedes (Stegomyia) flavopictus complex (Diptera: Culicidae) in Japan by sequence analysis of the internal transcribed spacers of ribosomal DNA. J Med Entomol. 2002;39(3):461-8.

34. Tanaka K. A revision of the adult and larval mosquitoes of Japan (including the Ryukyu Archipelago and the Ogasawara Islands) and Korea (Diptera: Culicidae). Contrib Am Entomol Inst. 1979;16:987.

35. Hong H-K, Shim J-C, Shin H-K, Yun Y-H. Hibernation studies of forest mosquitoes in Korea, 1971. Korean J Entomol. 1971;1 (1):13-6.

36. Shin J, Jung J. Complete mitochondrial genome of Aedes flavopictus (Yamada, 1921) (Diptera: Culicidae) collected in South Korea. Mitochondrial DNA B. 2021;6(1):265-7.

37. Mogi M. Variation in cold hardiness of nondiapausing eggs of nine Aedes (Stegomyia) species (Diptera: Culicidae) from eastern Asia and Pacific islands ranging from the tropics to the cool-temperate zone. J Med Entomol. 2011;48(2):212-22.

38. Doggett S, Clancy J, Haniotis J, Russell R, Hueston L, Marchetti M, et al. The New South Wales Arbovirus surveillance and mosquito monitoring program 2018-2019 annual report. New South Wales Government, Sydney, Australia. 2019. p. 36.

39. Ibáñez-Justicia A, van de Vossenberg B, van den Biggelaar R, Voogd J, Metz E, Jacobs F, et al. Detection of Aedes flavopictus (Yamada, 1921), Netherlands, June 2019. Euro Surveill. 2019;24(30):1900433.

40. Chaves LF. Globally invasive, withdrawing at home: Aedes albopictus and Aedes japonicus facing the rise of Aedes flavopictus. Int J Biometeorol. 2016;60(11):1727-38.

41. Chung S-J, Ko S-H, Ko E-M, Lim E-J, Kim Y-S, Lee W-G, et al. Mosquito prevalence and flavivirus infection rates in Gangwon-do, Republic of Korea. Korean J Appl Entomol. 2019;58(2):89-99.

42. Kim T-K, Jang C-W, Kim H, Roh JY, Ju Y. Collection status of infectious disease vectors. Public Health Wkly Rep. 2017;10(13):308-12.

43. Yang S-C, Kim H, Lee W-G, Cho S-H. Monitoring of population density of the Japanese encephalitis vector, Culex tritaeniorhynchus (Diptera: Culicidae) in South Korea in 2018. Public Health Wkly Rep. 2019;12(22):712-6.

44. Srisawat R, Phanitchat T, Komalamisra N, Tamori N, Runtuwene L, Noguchi K, et al. Susceptibility of Aedes flavopictus miyarai and Aedes galloisi mosquito species in Japan to dengue type 2 virus. Asian Pac J Trop Biomed. 2016;6(5):446-50.

45. Eshita Y, Kuriahara T, Ogata T, Ova A. Studies on the susceptibility of mosquitoes to dengue virus. I. Susceptibility of Japanese mosquitoes to the virus. Jpn J Sanit Zool. 1982;33(1):61-4.

46. Lee KW. Checklist of mosquitoes (Culicidae) in Korea. Korean J Parasitol. 1987;25(2):207-9.

47. Maekawa Y, Tsuda Y, Sawabe K. A nationwide survey on distribution of mosquitoes in Japan. Med Entomol Zool. 2016;67(1):1-12.

48. Chaves LF, Friberg MD. Aedes albopictus and Aedes flavopictus (Diptera: Culicidae) pre-imaginal abundance patterns are associated with different environmental factors along an altitudinal gradient. Curr Res Insect Sci. 2021;1:100001.

49. Alam MS, Tuno N. A study comparing the growth rates of two related species, Aedes albopictus and Aedes flavopictus (Diptera: Culicidae) at different temperature regimes. Med Entomol Zool. 2020;71(1):25-30.

50. Sultana A, Sunahara T, Tsurukawa C, Tuno N. Reproductive interference between Aedes albopictus and Aedes flavopictus at a place of their origin. Med Vet Entomol. 2020;35(1):59-67.

51. Yamada S. Descriptions of ten new species of Aëdes found in Japan, with notes on the relation between some of these mosquitoes and the larva of Filaria bancrofti Cobbold. Annot Zool Jpn. 1921;10:45-81.

52. Sota T, Mogi M. Origin of pitcher plant mosquitoes in Aedes (Stegomyia): a molecular phylogenetic analysis using mitochondrial and nuclear gene sequences. J Med Entomol. 2006;43(5):795-800.

53. Mogi M, Armbruster PA, Tuno N, Aranda C, Yong HS. The climate range expansion of Aedes albopictus (Diptera: Culicidae) in Asia inferred from the distribution of Albopictus subgroup species of Aedes (Stegomyia). J Med Entomol. 2017:54(6):1615-25.

54. Forman S, Hungerford N, Yamakawa M, Yanase T, Tsai H, Joo Y, et al. Climate change impacts and risks for animal health in Asia. Rev Sci Tech Off Int Epiz. 2008;27:581-97.

55. Li F, Kwon YS, Bae MJ, Chung N, Kwon TS, Park YS. Potential impacts of global warming on the diversity and distribution of stream insects in South Korea. Conserv Biol. 2014;28(2):498-508. 
56. Gaffigan T, Wilkerson R, Pecor J, Stoffer J, Anderson T. Systematic catalog of Culicidae. Walter Reed Biosystematic Unit. 2017. www.mosquitoca talog.org.

57. Lee GW. A revision of the illustrated taxonomic keys to genera and species of mosquito larvae of Korea. (Diptera: Culicidae). In: 5th Med. Detach. 168th Med. Battalion. 18th Med. Cmd. U.S. Army. APO AP; 1998.

58. Kang S, Jung J, Lee S, Hwang H, Kim W. The polymorphism and the geographical distribution of the knockdown resistance $(k d r)$ of Anopheles sinensis in the Republic of Korea. Malar J. 2012;11(1):151

59. Lee SH, Nam KW, Jeong JY, Yoo SJ, Koh Y-S, Lee S, et al. The effects of climate change and globalization on mosquito vectors: evidence from Jeju Island, South Korea on the potential for Asian tiger mosquito (Aedes albopictus) influxes and survival from Vietnam rather than Japan. PLoS ONE. 2013;8(7):e68512.

60. Lee E, Yang S-C, Kim T-K, Noh B-E, Lee HS, Kim H, et al. Geographical genetic variation and sources of Korean Aedes albopictus (Diptera: Culicidae) populations. J Med Entomol. 2020;57(4):1057-68.

61. Yeom J-S. Current status and outlook of mosquito-borne diseases in Korea. J Korean Med Assoc. 2017;60(6):468-74.

62. KCDC. Infectious diseases surveillance yearbook. 2019. http://www.kdca. go.kr/npt/biz/npp/portal/nppPblctDtaMain.do?pblctDtaSeAt=1.

63. Maynard AJ, Ambrose L, Cooper RD, Chow WK, Davis JB, Muzari MO, et al. Tiger on the prowl: invasion history and spatio-temporal genetic structure of the Asian tiger mosquito Aedes albopictus (Skuse 1894) in the Indo-Pacific. PLoS Negl Trop Dis. 2017;11(4):e0005546.

64. Birungi J, Munstermann LE. Genetic structure of Aedes albopictus (Diptera: Culicidae) populations based on mitochondrial ND5 sequences: evidence for an independent invasion into Brazil and United States. Ann Entomol Soc Am. 2002;95(1):125-32.

65. Rozas J, Ferrer-Mata A, Sánchez-DelBarrio JC, Guirao-Rico S, Librado P, Ramos-Onsins SE, et al. DnaSP 6: DNA sequence polymorphism analysis of large data sets. Mol Biol. 2017;34(12):3299-302.

66. Excoffier $\mathrm{L}$, Lischer HE. Arlequin suite ver 3.5: a new series of programs to perform population genetics analyses under Linux and Windows. Mol Ecol Resour. 2010;10(3):564-7.

67. Peakall R, Smouse PE. GenAlEx 6.5: genetic analysis in Excel. Population genetic software for teaching and research-an update. J Bioinform. 2012;28(19):2537-9.

68. Leigh JW, Bryant D. POPART: full-feature software for haplotype network construction. Methods Ecol Evol. 2015;6(9):1110-6.

69. Tajima F. Statistical method for testing the neutral mutation hypothesis by DNA polymorphism. Genetics. 1989;123(3):585-95.

70. Fu Y-X. Statistical tests of neutrality of mutations against population growth, hitchhiking and background selection. Genetics. 1997; 147(2):915-25

71. Armbruster P, Damsky WE Jr, Giordano R, Birungi J, Munstermann LE, Conn JE. Infection of new-and old-world Aedes albopictus (Diptera: Culicidae) by the intracellular parasite Wolbachia: implications for host mitochondrial DNA evolution. J Med Entomol. 2003:40(3):356-60.

72. Park CH, Lim H, Kim H, Lee WG, Roh JY, Park MY, et al. High prevalence of Wolbachia infection in Korean populations of Aedes albopictus (Diptera: Culicidae). J Asia Pac Entomol. 2016;19(1):191-4.

73. Atyame CM, Delsuc F, Pasteur N, Weill M, Duron O. Diversification of Wolbachia endosymbiont in the Culex pipiens mosquito. Mol Biol Evol. 2011;28(10):2761-72.

74. Rašić G, Schama R, Powell R, Maciel-de Freitas R, Endersby-Harshman NM, Filipović l, et al. Contrasting genetic structure between mitochondrial and nuclear markers in the dengue fever mosquito from Rio de Janeiro: implications for vector control. Evol Appl. 2015;8(9):901-15.
75. Thu HM, Aye KM, Thein S. The effect of temperature and humidity on dengue virus propagation in Aedes aegypti mosquitos. Southeast Asian J TroP Med. 1998:29(2):280-4.

76. Lee $\mathrm{H}$, Kim JE, Lee S, Lee $\mathrm{CH}$. Potential effects of climate change on dengue transmission dynamics in Korea. PLoS ONE. 2018;13(6):e0199205.

77. Kaufmann C, Collins LF, Brown MR. Influence of age and nutritional status on flight performance of the Asian tiger mosquito Aedes albopictus (Diptera: Culicidae). Insects. 2013;4(3):404-12.

78. Delatte H, Toty C, Boyer S, Bouetard A, Bastien F, Fontenille D. Evidence of habitat structuring Aedes albopictus populations in Réunion Island. PLoS Negl Trop Dis. 2013;7(3):e2111.

79. Motoki MT, Fonseca DM, Miot EF, Demari-Silva B, Thammavong P, Chonephetsarath S, et al. Population genetics of Aedes albopictus (Diptera: Culicidae) in its native range in Lao People's Democratic Republic. Parasites Vectors. 2019;12(1):1-12.

80. Porretta D, Mastrantonio V, Bellini R, Somboon P, Urbanelli S. Glacial history of a modern invader: phylogeography and species distribution modelling of the Asian tiger mosquito Aedes albopictus. PLoS ONE. 2012;7(9):1-9.

81. Sota T, Mogi M. Survival time and resistance to desiccation of diapause and non-diapause eggs of temperate Aedes (Stegomyia) mosquitoes. Entomol Exp. 1992;63(2):155-61.

82. Wright S. Size of population and breeding structure in relation to evolution. Science. 1938;87:430-1.

83. Usmani-Brown S, Cohnstaedt L, Munstermann LE. Population genetics of Aedes albopictus (Diptera: Culicidae) invading populations, using mitochondrial nicotinamide adenine dinucleotide dehydrogenase subunit 5 sequences. Ann Entomol Soc Am. 2009;102(1):144-50.

84. Nater A, Arora N, Greminger MP, van Schaik CP, Singleton I, Wich SA, et al. Marked population structure and recent migration in the critically endangered Sumatran orangutan (Pongo abelii). J Hered. 2013;104(1):2-13.

85. Vandewoestijne S, Baguette M, Brakefield PM, Saccheri I. Phylogeography of Aglais urticae (Lepidoptera) based on DNA sequences of the mitochondrial $\mathrm{COI}$ gene and control region. Mol Phylogenet Evol. 2004;31(2):630-46.

86. Overgaard $\mathrm{H}$. Malaria mosquito resistance to agricultural insecticides: risk area mapping in Thailand, vol. 103. Colombo: IWMI; 2006

87. Thomas SM, Obermayr U, Fischer D, Kreyling J, Beierkuhnlein C. Low-temperature threshold for egg survival of a post-diapause and non-diapause European aedine strain, Aedes albopictus (Diptera: Culicidae). Parasites Vectors. 2012;5(1):1-7

88. De Majo MS, Fischer S, Otero M, Schweigmann N. Effects of thermal heterogeneity and egg mortality on differences in the population dynamics of Aedes aegypti (Diptera: Culicidae) over short distances in temperate Argentina. J Med Entomol. 2013;50(3):543-51.

89. Chang L-H, Hsu E-L, Teng H-J, Ho C-M. Differential survival of Aedes aegypti and Aedes albopictus (Diptera: Culicidae) larvae exposed to low temperatures in Taiwan. J Med Entomol. 2007;44(2):205-10.

90. Sherpa S, Blum MG, Capblancq T, Cumer T, Rioux D, Després L. Unravelling the invasion history of the Asian tiger mosquito in Europe. Mol Ecol. 2019:28(9):2360-77.

91. Athrey G, Hodges TK, Reddy MR, Overgaard HJ, Matias A, Ridl FC, et al. The effective population size of malaria mosquitoes: large impact of vector control. PLoS Genet. 2012;8(12):e1003097.

\section{Publisher's Note}

Springer Nature remains neutral with regard to jurisdictional claims in published maps and institutional affiliations. 